\title{
Nanomechanical Comparison of Commonly Used Dental Crown Cements to a Newly Developed One
}

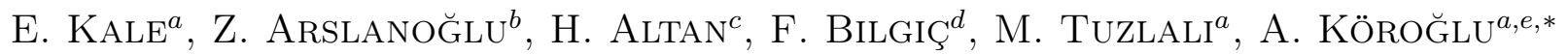 \\ AND S. ÖZARSLAN ${ }^{f}$ \\ ${ }^{a}$ Mustafa Kemal University, Faculty of Dentistry, Department of Prosthodontics, Hatay, Turkey \\ ${ }^{b}$ Mustafa Kemal University, Faculty of Dentistry, Department of Paediatric Dentistry, Hatay, Turkey \\ ${ }^{c}$ Gaziosmanpaşa University, Faculty of Dentistry, Department of Paediatric Dentistry, Tokat, Turkey \\ ${ }^{d}$ Mustafa Kemal University, Faculty of Dentistry, Department of Orthodontics, Hatay, Turkey \\ ${ }^{e}$ Mustafa Kemal University, Faculty of Dentistry, Department of Periodontology, Hatay, Turkey \\ ${ }^{f}$ Mustafa Kemal University, Department of Physics, Hatay, Turkey
}

\begin{abstract}
The main goal of nanoindentation tests is to obtain elastic modulus and hardness of the specimen material from load-displacement measurements. With this study, it was aimed to establish a quantitative relationship between the nanomechanical properties of commonly used dental cements in comparison to a newly developed crown cement and to predict its performance potential. Nanomechanical properties of polycarboxylate cement (PCC), glass-ionomer cement (GIC), dual-cure self-adhesive cement (SAC) and a newly developed glass-carbomer cement (GCC) were investigated by nanoindentation tests. All samples were fabricated according to their respective manufacturer's instructions. Available damage on the surface due to manipulation was removed by grinding with 1200,2400 and 4000 grit sandpaper, and then polishing on 6,3, and $1 \mu \mathrm{m}$ diamond-lap-wheel was performed. Nano-mechanical measurements were done using nanoindenter machine with resolution less than $1 \mathrm{nN}$ and displacement resolution of $0.04 \mathrm{~nm}$. Berkovich diamond indenter tip was used for the nanoindentation tests. For each indentation, a set of nanoindentation tests at least on 6 different locations per specimen surface were performed to obtain more representative mean results. Indentation test load-displacement curves were analysed using Oliver-Pharr method, and one-way ANOVA or Kruskal-Wallis test, following Kolmogorov-Smirnov and Shapiro-Wilk, was used to compare the results. Nanohardness $\left(H_{\text {nano }}\right)$ values were $0.52 \pm 0.25,0.45 \pm 0.18,1.03 \pm 0.82$ and $0.43 \pm 0.18$ GPa for GIC, GCC, PCC, and SAC, respectively. Reduced elastic modulus $\left(E_{r}\right)$ values were $9.51 \pm 6.17,11.77 \pm 5.04,27.37 \pm 20.61$, $10.33 \pm 5.08 \mathrm{GPa}$ for GIC, GCC, PCC, and SAC, respectively. There was no statistical difference between the tested materials. PCC was the hardest, and GIC was the least hard material, whereas the newly developed GCC was the second, in terms of $H_{\text {nano, }}$, before SAC. PCC also had the highest $E_{r}$ mean, compared to the other dental crown cements, suggesting lower elastic properties. SAC was more elastic than GCC and less elastic than GIC. GCC had the second highest $E_{r}$, standing closer to SAC and GIC. Within the limitations of the current study, it can be concluded that the newly developed glass-carbomer cement is comparable to the other tested commonly used dental crown cements, regarding $H_{\text {nano }}$ and $E_{r}$.
\end{abstract}

DOI: $10.12693 /$ APhysPolA.132.954

PACS/topics: $62.20 .-\mathrm{x}, 62.20 . \mathrm{Qp}, 62.20 . \mathrm{de}$

\section{Introduction}

Dental cements are widely used luting agents for fixation of dental crowns and other fixed dental prostheses in dentistry. There is a wide range of cements available on the market from conventional water-based to contemporary resin-based cements [1]. Today, among the most commonly used dental cements are zinc-polycarboxylate cement, glass-ionomer cement and self-adhesive resin cement [1].

Classical polycarboxylate cement was the first cement system developed with a potential for adhesion to tooth structure [2]. Conventional glass-ionomer cements were developed based on the favourable properties of both silicate and polycarboxylate cements [3]. They

*corresponding author; e-mail: dtkoroglu@hotmail.com undergo setting through an acid-base reaction between an ion-leachable glass and aqueous polyacid and can chemically bond to enamel and dentin [4]. Moreover, they have an ability to release fluoride with superior physical and mechanical properties $[1,5,6]$. Self-adhesive resin cements are the latest of the contemporary resin cements [7]. They contain specific adhesive monomers that are sufficiently acidic to produce their self-adherence to dental hard tissue [7].

Despite their clinically acceptable success, all these materials have some clinical limitations, such as a prolonged setting time, moisture sensitivity during initial setting, dehydration and rough surface characteristics, which can potentially reduce their mechanical resistance $[8,9]$. In the last few years, a new type of dental cement has been introduced to the market - class-carbomer cement - that has been claimed by its manufacturer to overcome the negative properties of glass-ionomer cements, due to its improved physical properties [10]. 
This new material contains nano-sized glass particles and fluor-apatite, as filler, and sets chemically while being optimized for heat curing [10].

While any cement has its advantages, dentists must carefully consider which is the most suitable for an individual case, depending on the material and substrate to be bonded $[11,12]$. Successful cement should be easy to use, excellent in adhesion with mechanical properties to withstand masticatory or parafunctional forces, and a long-term stability in the warm and wet oral environment, it should also be aesthetic and biocompatible [11]. The real difference in the performance of dental crown cements can be established by means of long-term clinical evidence-based data. However, before starting an extensive research, basic mechanical properties of new materials on the market can easily be compared to those of materials that have been on sale for a long time and have had the privilege to be observed and studied clinically for a while.

Hardness as a physical property of a solid is the resistance to potential penetration of the mass by any harder material or the resistance of the tested material to wear, scratching, cutting and plastic deformation [13]. It covers several properties like resistance to deformation, friction and abrasion. It combines elastic and plastic properties and can be understood as some measure of resistance to surface contact deformation $[13,14]$. Indentation hardness, as a principal parameter for mechanical characterization of solid materials, has been commonly used as a technique to measure the mechanical properties of dental materials [14]. It is defined in macro-, microor nano-scale according to the indentation forces applied and the displacement of the indenter observed. Nanoindentation tests measure hardness by using indentation force on nano-scale, by measuring the depth of indention in microns. These tests are based on new technology that allows for precise and controlled indentation forces along with precise measurement of the indentation depths [15]. Measurement procedures consist of pressing the indenter into surface with constant load or strain rate, recording indenter displacement as a function of load during loading/unloading, and of finally, calculating the hardness from the load-displacement curve and elastic modulus of the material from the unloading curve [15]. The main goal of nanoindentation tests is to easily determine elastic modulus and hardness, as basic mechanical properties of newly developed materials from load-displacement measurements.

The purpose of this study was to establish a quantitative relationship between the nanomechanical properties of commonly used dental cements in comparison to a newly developed crown cement in terms of nanohardness $H_{\text {nano }}$ and reduced elastic modulus $E_{r}$, and to predict its performance potential, based on previously published dental literature, regarding materials present on the market for a longer time. The null hypothesis was that there would be no difference in tested mechanical properties between commonly used and newly developed dental crown cements.

\section{Materials and methods}

Four different dental crown luting cements were tested in this study $(n=6)$. Specimens consisted of conventional glass-ionomer cement (GIC), newly developed glasscarbomer cement (GCC), classic polycarboxylate cement (PCC) and contemporary dual-cure self-adhesive cement (SAC) (Table I)

TABLE I

Brand name, lot number, specification and manufacturer information of the luting cements tested in the study.

\begin{tabular}{c|c|c}
\hline \hline Material brand & $\begin{array}{c}\text { Material type } \\
\text { (Lot number) }\end{array}$ & Material manufacturer \\
\hline Voco Meron & Glass-Ionomer Cement & VOCO, Germany \\
GCP Glass Crown Cement & $\begin{array}{c}\text { Glass-Carbomer Cement } \\
\text { (7302245) }\end{array}$ & GCP Dental, Netherlands \\
Adhesor Carbofine & $\begin{array}{c}\text { Zinc-Polycarboxylate Cement } \\
\text { (liquid/powder: 2480086-2) }\end{array}$ & Spofa Dental, Czech Republic \\
Panavia SA Cement (Automix) & $\begin{array}{c}\text { Self-Adhesive Resin Composite Cement } \\
(2 \mathrm{~J} 0002)\end{array}$ & Kuraray, Japan \\
\hline
\end{tabular}

Four 10 mm-thick parallel-edged polymethylmethacrylate (PMMA) cylinder blocks with diameter of $50 \mathrm{~mm}$ were fabricated with 7 cavities of $2 \mathrm{~mm}$ depth and diameter of $10 \mathrm{~mm}$ on one of the flat surfaces of each. A thin layer of cyanoacrylate adhesive was applied to the inner surface of the cavities and each of seven cavities per block was randomly filled with one of the test materials. All the materials were applied strictly in accordance with the manufacturer's instructions.

Blue light of $1400 \mathrm{~mW} / \mathrm{cm}^{2}$ was used for $20 \mathrm{~s}$ (VALO LED; Ultradent, USA) for the curing procedure of group SAC. Capsule mixer (10 s) (GCP CarboMIX; GCP Den- 
tal, Nederland), capsule applicator (GCP CarboCAP; GCP Dental) and light-heat-curing $\left(1400 \mathrm{~mW} / \mathrm{cm}^{2}\right.$ for $60 \mathrm{~s}$ ) device (GCP CarboLed Lamp; GCP Dental) was used for the application and curing of GCC group. Samples were stored at $100 \%$ humidity environment in room temperature for 24 hours after preparation.

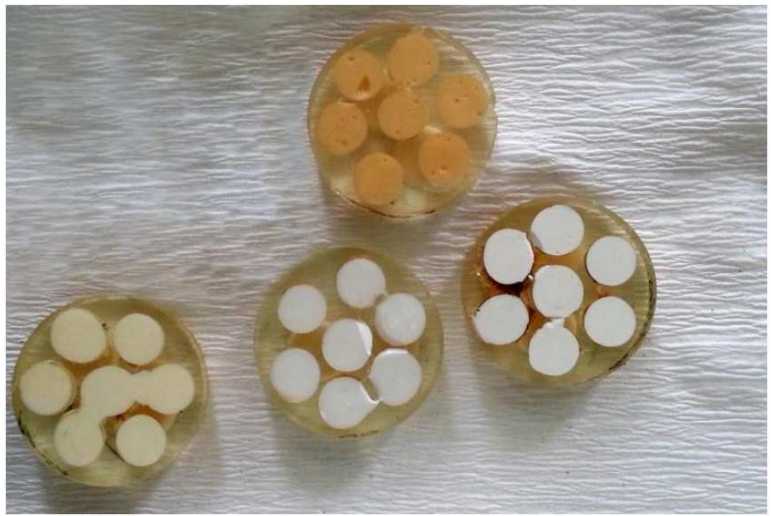

Fig. 1. Prepared samples inside PMMA cylinders, for each group.

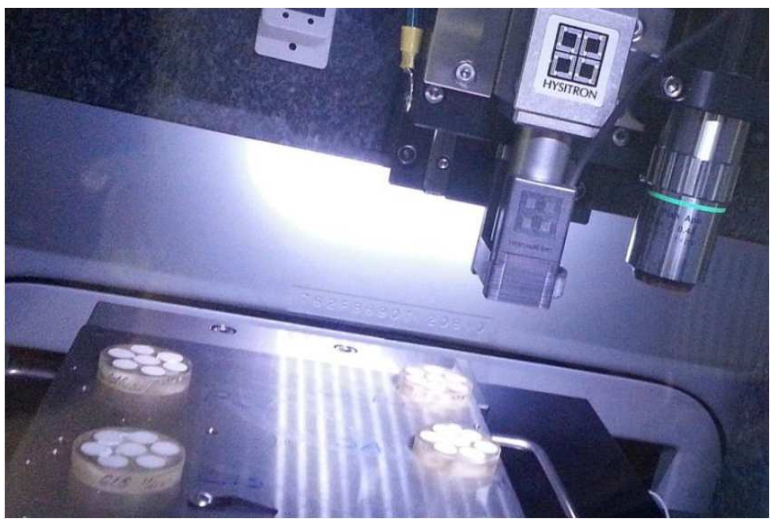

Fig. 2. Samples in nanoindenter machine.

Prior to testing, material surfaces were aligned flat to the surface of their corresponding carrying PMMA cylinders to ensure parallelism between samples, using 1200 , 2400 and 4000 grit ( $\mathrm{SiC}$ ) sandpaper discs and 6, 3 and $1 \mu \mathrm{m}$ diamond-lap-wheels, consecutively, on a mechanical device (Fig. 1). Nanomechanical measurements were done using nanoindenter machine (TI 950 TriboIndenter; Hysitron, USA) with resolution less than $1 \mathrm{nN}$ and displacement resolution of $0.04 \mathrm{~nm}$ (Fig. 2). Berkovich diamond indenter tip was used for $H_{\text {nano }}$ and reduced elastic modulus $E_{r}$ tests. The tip was calibrated using a fused quartz reference sample. One of the specimens on each PMMA cylinder was also used for calibration purposes before the test start in each group. For an indentation, a set of nanoindentation tests, at least on six different locations per specimen surface, with maximum load of $6000 \mu \mathrm{N}$ under a loading/unloading rate of $1200 \mu \mathrm{N} \mathrm{s}^{-1}$, with load held at maximum value for $2 \mathrm{~s}$, were performed to obtain more representative mean results. To record the topographic images of the indents, the nanoindenter was also operated in scanning probe mode (Fig. 3). Indentation test load-displacement curves were analysed using Oliver-Pharr method [15-17].

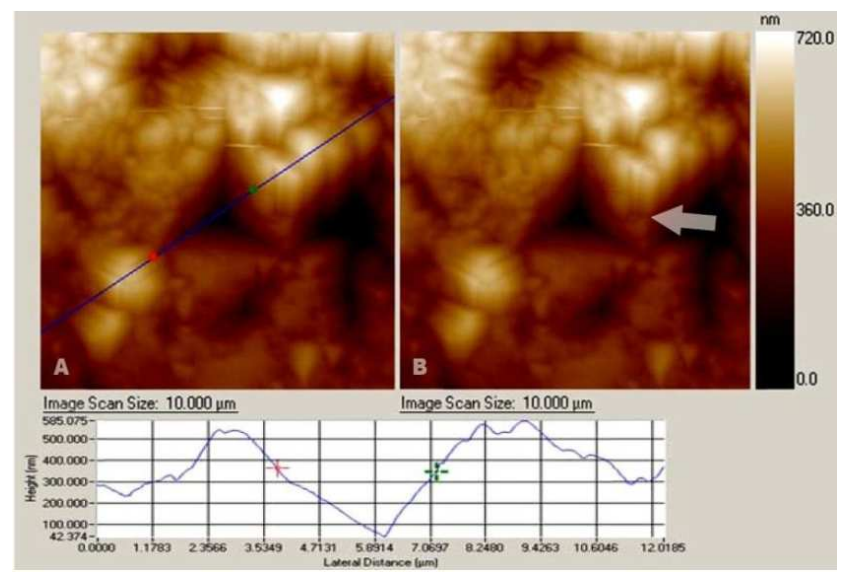

Fig. 3. Morphological topography of an indent (arrow) (B), and computation of indent depth and contact distance $(\mathrm{A})$.

In the current model, contact area $\left(A_{\mathrm{c}}\right)$ and nanohardness $\left(H_{\text {nano }}\right)$ were computed with the following formula,

$$
A_{\mathrm{c}}=24.5 h_{\mathrm{c}}^{2} H_{\text {nano }}=\frac{P_{\max }}{A},
$$

where $P_{\max }$ is the maximum test load and $A_{\mathrm{c}}$ is the projected contact area at $P_{\max }$. The reduced elastic modulus $E_{r}$ was computed with the following formula,

$$
E_{r}=\frac{\sqrt{\pi}}{2} \frac{S}{\sqrt{24.5 h_{\mathrm{c}}}},
$$

where $S$ is the contact stiffness, acquired from the initial slope on the unloading curve at $P_{\max }$.

Kolmogorov-Smirnov and Shapiro-Wilk methods were used to assess the homogeneity of variance of nanoindentation test results and one-way ANOVA along with Kruskal-Wallis tests were used accordingly by means of statistical software (Statistical Package for the Social Sciences v.15; SPSS, USA) at a level of significance $\alpha=0.05$.

\section{Results}

Kolmogorov-Smirnov and Shapiro-Wilk tests have revealed normal distribution for $H_{\text {nano }}$ but not for $E_{r}$. The results from one-way ANOVA for $H_{\text {nano }}$ and KruskalWallis for $E_{r}$ did not show any statistical difference between the tested materials. Detailed data of the evaluated physical properties of the luting cements, regarding measurements, calculations and statistical analyses, are given in Table II trough Table V. The obtained indentation test load-displacement curves are shown in Fig. 4.

Among the tested dental crown luting cements, PCC was the hardest, and GIC was the least hard, whereas the newly developed GCC was the second in terms of $H_{\text {nano }}$ before SAC (Fig. 5). PCC also had the highest mean $E_{r}$ 
TABLE II

Mean \pm standard deviation (SD), standard error (SE), median and minimum-maximum range of $E_{r}$ for the tested materials $(\mathrm{GPa})$. Specimen number: 6 .

\begin{tabular}{c|c|c|c|c|c}
\hline \hline Group & $\begin{array}{c}\text { Mean } \\
(\mathrm{SD})\end{array}$ & SE & Med & Min & Max \\
\hline GIC & 9.51 & 2.52 & 6.72 & 4.81 & 20.70 \\
(Glass-Ionomer Cement) & $(6.17)$ & & & & \\
GCC & 11.77 & 2.06 & 11.24 & 6.36 & 18.36 \\
(Glass-Carbomer Cement) & $(5.04)$ & & & & \\
PCC & 27.37 & 8.42 & 18.98 & 9.61 & 58.93 \\
(Polycarboxylate Cement) & $(20.61)$ & & & & \\
SAC & 10.33 & 2.07 & 8.71 & 6.46 & 20.46 \\
(Self-Adhesive Cement) & $(5.08)$ & & & &
\end{tabular}

TABLE III

Mean \pm standard deviation (SD), standard error (SE), median and minimum-maximum range of $H_{\text {nano }}$ for the tested materials (GPa). Specimen number: 6 .

\begin{tabular}{c|c|c|c|c}
\hline \hline Group & $\begin{array}{c}\text { Mean } \\
(\mathrm{SD})\end{array}$ & SE & Min & Max \\
\hline GIC & $\begin{array}{c}0.52 \\
(0.25)\end{array}$ & 0.10 & 0.21 & 0.85 \\
$\begin{array}{c}\text { (Glass-Ionomer Cement) } \\
\text { GCC }\end{array}$ & 0.45 & 0.07 & 0.27 & 0.77 \\
$\left(\begin{array}{c}(0.18) \\
\text { (Glass-Carbomer Cement) } \\
\text { PCC }\end{array}\right.$ & & & \\
(Polycarboxylate Cement) & $(0.82)$ & 0.34 & 0.15 & 2.02 \\
SAC & 0.43 & 0.07 & 0.27 & 0.74 \\
(Self-Adhesive Cement) & $(0.18)$ & & &
\end{tabular}

TABLE IV

Kruskal-Wallis results for $E_{r}(P<0.05)$. Specimen number: 6

\begin{tabular}{c|c|c|c|c}
\hline \hline Group & $\begin{array}{c}\text { Mean } \\
\text { rank }\end{array}$ & df & $\begin{array}{c}\text { Chi } \\
\text { square }\end{array}$ & $\begin{array}{c}\text { Asymp. sig. } \\
P(\alpha=0.05)\end{array}$ \\
\hline GIC & 8.33 & 3 & 7.380 & 0.061 (NS) \\
$\begin{array}{c}\text { (Glass-Ionomer Cement) } \\
\text { GCC }\end{array}$ & 12.33 & & & \\
$\begin{array}{c}\text { (Glass-Carbomer Cement) } \\
\text { PCC }\end{array}$ & 18.83 & & & \\
$\begin{array}{c}\text { (Polycarboxylate Cement) } \\
\text { SAC }\end{array}$ & 10.50 & & & \\
(Self-Adhesive Cement) & & & & \\
\hline
\end{tabular}

NS: non-significant.

TABLE V

One-way ANOVA results for $H_{\text {nano }}(P<0.05)$.

\begin{tabular}{c|c|c|c|c|c}
\hline \hline $\begin{array}{c}\text { Source of } \\
\text { variation }\end{array}$ & $\begin{array}{c}\text { Sum of } \\
\text { squares }\end{array}$ & df & $\begin{array}{c}\text { Mean } \\
\text { square }\end{array}$ & $\mathrm{F}$ & $P(\alpha=0.05)$ \\
\hline Between groups & 1.443 & 3 & 0.481 & 2.394 & $0.099(\mathrm{NS})$ \\
Within groups & 4.019 & 20 & 0.201 & & \\
Total & 5.462 & 23 & & & \\
\hline
\end{tabular}

NS: non-significant.

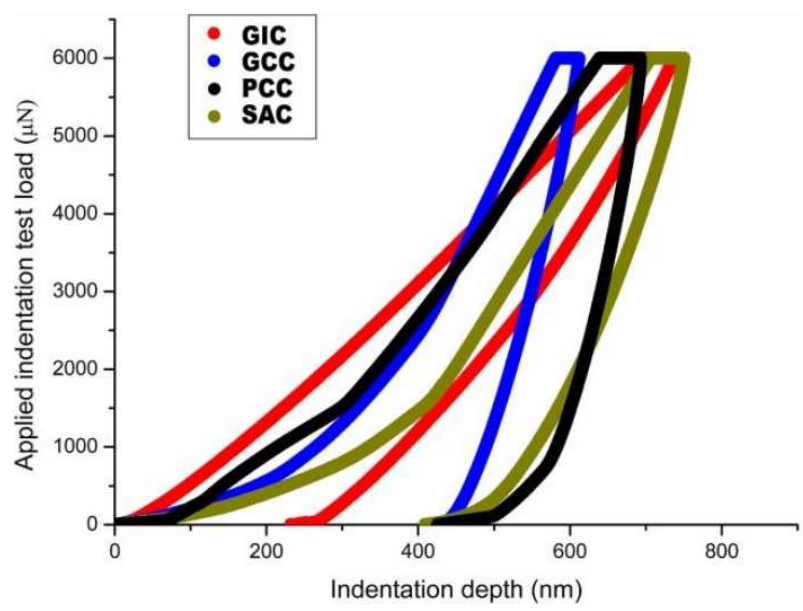

Fig. 4. Indentation test load versus indentation depth for the tested materials.

compared to others, suggesting lower elastic properties. SAC was more elastic than GCC and less elastic than GIC (Fig. 6). GCC had the second highest $E_{r}$ standing closer to SAC and GIC.

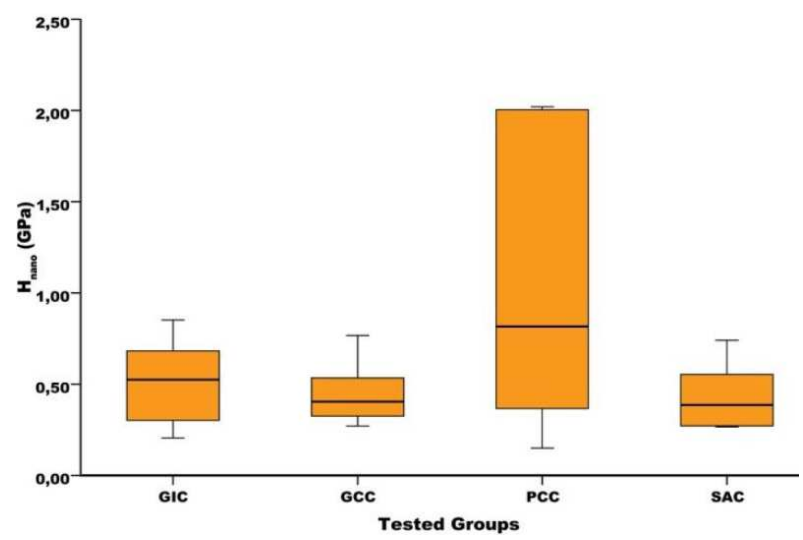

Fig. 5. Box-plot comparison diagrams of $H_{\text {nano }}$ for tested materials.

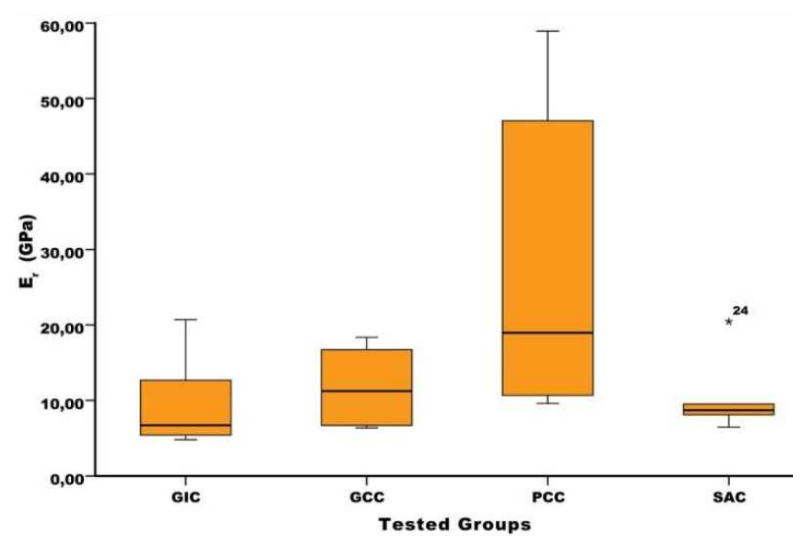

Fig. 6. Box-plot comparison diagrams of $E_{r}$ for tested materials. 


\section{Discussion}

The nanomechanical comparison in terms of $H_{\text {nano }}$ and $E_{r}$ of the common dental crown cements (GIC, PCC and $\mathrm{SAC})$ to the newly developed one (GCC) used in this study had shown no statistical differences between each other, therefore the null hypothesis set up at the beginning of the study was accepted.

The main limitation of the current study was the low number of specimens per group. Although, a mean of at least 6 indentations per specimen was considered while testing in each group, other parameters, like standard deviation, for example, remained undefined regarding these mean values. This deficiency eradicated the chance of implementation of a power analysis to the statistical evaluation and limited the indentation test number to 6 (number of specimens per group), whereas the number of indentations per group was actually $6 \times 6=36$. This should be taken into account before generalizing from the results of the present study.

Glass-carbomer cement is relatively new on the market and is very scarcely represented in dental literature [17], whereas there are quite a lot of studies investigating mechanical properties of glass-ionomer, polycarboxylate and resin cements $[8,9,11]$. Rosenstiel et al. have reviewed the mechanical properties of different dental luting cements and have ordered the materials, considering the compressive strength, from low to high, as polycarboxylat, glass-ionomer and resin cements [11]. They also have reported the elastic modulus of $11.2 \mathrm{GPa}$ for glassionomer and up to $9.8 \mathrm{GPa}$ for resin cements [11].

Those findings are not quite in correlation with the results of the current study, although, the resulting data for elastic modulus is comparable to those (GIC: $9.51 \mathrm{GPa}$; SAC: $10.33 \mathrm{GPa}$ ) obtained in the current study. Attar et al. have investigated the mechanical properties of luting cements and reported a higher elastic modulus after 24 hours for dual-cure resin cements than for glassionomer cement [9]. Those results are in line with the finding of the present study. $\mathrm{Li}$ and White have also investigated the mechanical properties of dental luting agents after 24 hours and found that polycarboxylat cement had higher elastic modulus than resin cement, nevertheless, the glass-ionomer cement tested in that study was less elastic compared to both materials [8].

The present study had also resulted in higher elastic modulus mean values for polycarboxylat cement compared to resin cement, but the glass-ionomer in this study was found to be more elastic than both of these materials. In a recent study by Altan et al., glass-ionomer and glass-carbomer cements were compared in terms of $H_{\text {nano }}$ [17]. The results have revealed higher mean values for glass-ionomer over glass-carbomer cement, being completely in accordance with those of the present study.

The direct comparison of the results of this study to previous studies is difficult because many different products of different manufacturers with different formulation and structure have been evaluated as glass-ionomer, polycarboxylat or resin cements. The fact that GCC is somewhere between GIC, PCC and SAC in terms of $H_{\text {nano }}$ and $E_{r}$, comments for dental crown cement with reliable mechanical properties. Glass-ionomer, polycarboxylat and resin cements are well documented in the literature with acceptable long-term performance ability $[11,12]$. The results of the current study suggest an acceptable performance potential, considering the GCC dental crown luting agent. Further investigations are encouraged.

\section{Conclusions}

Within the limitations of the current study, it can be concluded that the newly developed glass-carbomer cement is comparable to the other tested, commonly used, dental crown cements, regarding $H_{\text {nano }}$ and $E_{r}$.

\section{Acknowledgments}

Authors express sincere appreciation to Dr. Osman ŞAHIN for his kind cooperation during the preparation of this work for presentation at the (3th) ICCESEN-2016 in Antalya, and Prof. Dr. Tacettin INANDI for performing the statistics of this article.

\section{References}

[1] A.M. Diaz-Arnold, M.A. Vargas, D.R. Haselton, J. Prosthet. Dent. 81, 135 (1999).

[2] D.C. Smith, Br. Dent. J. 125, 381 (1968).

[3] A.D. Wilson, S. Crisp, B.G. Lewis, J.W. McLean, Br. Dent. J. 142, 117 (1977).

[4] A.D. Wilson, H.J. Prosser, D.M. Powis, J. Dent. Res. 62, 590 (1983).

[5] G.J. Christensen, J. Am. Dent. Assoc. 120, 59 (1990).

[6] A.M. Diaz-Arnold, D.C. Holmes, D.W. Wistrom, E.J. Jr Swift, Dent. Mater. 11, 96 (1995).

[7] M.J. Tyas, M.F. Burrow, Aust. Dent. J. 49, 112 (2004).

[8] Z.C. Li, S.N. White, J. Prosthet. Dent. 81, 597 (1999).

[9] N. Attar, L.E. Tam, D. McComb, J. Prosthet. Dent. 89, 127 (2003).

[10] GCP Glass Crown Cement, User Instructions, Article no: 900.112, version 28-04-2011.

[11] S.F. Rosenstiel, M.F. Land, B.J. Crispin, J. Prosthet. Dent. 80, 280 (1998).

[12] E.E. Hill, J. Lott, Aust. Dent. J. 56 S1, 67 (2011).

[13] D. Tabor, Rev. Phys. Technol. 1, 145 (1970).

[14] D. Tabor, Br. J. Appl. Phys. 7, 159 (1956).

[15] W.C. Oliver, G.M. Pharr, J. Mater. Res. 19, 3 (2004).

[16] Z. Arslanoğlu, H. Altan, E. Kale, F. Bilgiç, O. Şahin, Acta. Phys. Pol. A 130, 388 (2016).

[17] H. Altan, F. Bilgic, Z. Arslanoglu, E. Kale, A. Köroğlu Kale, A. Altan, O. Sahin, Acta. Phys. Pol. A 130, 394 (2016). 